\title{
NA CONTRAMÃO DO NEOLIBERALISMO: SEM-TERRA E PIQUETEIROS ${ }^{1}$
}

\author{
Eliel Ribeiro Machado \\ Doutor em Ciências Sociais, \\ Professor de Ciências Política da Universidade Estadual de Londrina
}

\begin{abstract}
RESUMO
Este artigo aborda, fundamentalmente, os limites e potencialidades políticoideológicas de dois importantes movimentos sociais latino-americanos:os semterra (Brasil) e os piqueteiros (Argentina). A apropriação da política emancipadora pelos movimentos sociais possibilita que as relações sociais e de produção nos assentamentos do MST ou nos bairros populares dos piqueteiros ganhem novas dimensões políticas e ideológicas. Discutimos em cada um dos movimentos as "invenções democráticas" (democracia direta, horizontalidade, igualdade de gênero etc.) de que são protagonistas, bem como os seus limites dado o caráter de classe de suas bases sociais, ou seja, constituem-se de semi-assalariados (sem-terra) e de desempregados (sem-terra e piqueteiros).

Palavras-chave: Neoliberalismo. Movimentos Sociais.
\end{abstract}

\begin{abstract}
This article addresses, fundamentally, the limits and political-ideological potentialities of two important social Latin-American movements: the landless (MST) in Brazil and the picketers in Argentina. The appropriation of the emancipating politics by the social movements enables the social relations and the relations of production in the MST settlements or in the picketers' neighborhoods to gain new political and ideological dimensions. For each of these movements we discuss here the "democratic inventions" (direct democracy, horizontality, gender equality, etc.) of which they are the leading actors, as well as their limits in face of the class character of their social bases, that is, they are semi-employed (landless) and unemployed (landless and picketers).

Key-word: Neoliberalism. Social Movements.
\end{abstract}

\footnotetext{
${ }^{1}$ Este artigo é uma versão modificada e resumida de um dos capítulos de nossa tese de doutorado, intitulada Mal-estar da democracia no Brasil e na Argentina nos anos 90: lutas sociais na contramão do neoliberalismo. Devido aos limites de espaço, demos um caráter meramente expositivo ao texto, ou seja, não aprofundaremos as temáticas levantadas.

${ }^{2}$ Coordenador do GEPAL (Grupo de Estudos de Política da América Latina) e membro do NEILS (Núcleo de Estudos de Ideologias e Lutas Sociais do Programa de Estudos Pós-graduados em Ciências Sociais da Pontifícia Universidade Católica de São Paulo).
} 
Poucas pesquisas acadêmicas, no âmbito das Ciências Sociais, procuram analisar os objetivos dos movimentos sócio-políticos relacionando-os com as formas como se organizam para lutar por esses objetivos; tampouco se propõem a observar se há incongruências política e ideológica entre ambos. De forma sumária, procuramos compreender o processo dialético entre os objetivos pelos quais se luta e as formas como se luta por eles, a partir da análise das "invenções democráticas" dos sem-terra e dos piqueteiros.

Em maior ou menor medida, alguns movimentos sociais nos anos 90 imprimiram derrotas políticas importantes à implementação do projeto neoliberal. Se levarmos em conta os três elementos que compõem a "ideologia popular", ou seja, os elementos "inerentes", "derivados" e as "circunstâncias históricas", esses movimentos ampliaram suas bases de sustentação e empreenderam grandes mobilizações sociais, a despeito de toda a ofensiva política, ideológica e repressiva dos aparelhos policiais. ${ }^{3}$ Contra eles, ainda atuaram exemplarmente os grandes meios de comunicação televisivos e impressos. Mesmo assim, vários setores populares foram ganhos para as suas causas. Esses foram capazes politicamente de engendrar as próprias circunstâncias que impulsionaram o crescimento de suas mobilizações, num momento em que os governantes, sob a égide ideológica do "pensamento único", afirmavam o fim da luta de classes, dos movimentos sociais contestatórios, dos sindicatos, partidos etc. Ao lado dos discursos conservadores, forte repressão policial aos que teimavam em "fazer luta de classes".

Sob o contexto da hegemonia neoliberal, esses movimentos sociais começaram a desmascarar os limites da democracia burguesa e as novas formas de dominação política e ideológica. Os sem-terra e os piqueteiros, ao se oporem à dominação democrático-burguesa, apresentam, a partir de seus espaços de luta e resistência ${ }^{4}$, formas políticas, sociais, ideológicas e econômicas distintas e superiores às sociedades capitalistas, mesmo as mais avançadas. A esse conjunto de práticas sociais dos sem-terra e dos piqueteiros denominamos "invenções democráticas", expressão que tomamos de Lefort (1983), mas com um sentido diverso: referimo-nos às "invenções democráticas” dos

\footnotetext{
3 Sobre isso, apoiamo-nos em Rudé, para quem a "ideologia do protesto popular" é constituída pela fusão de três elementos essenciais: um deles, "propriedade inerente das classes populares", é o elemento "inerente", tradicional, baseado na experiência direta, na tradição oral etc. O segundo, é o "derivado", tomado de empréstimo de outros, como os Direitos do Homem, Soberania Popular etc. E o terceiro, são as "circunstâncias e experiências históricas", que ocorrem como precipitadoras de processos revolucionários (RUDÉ, 1982, p. 25-33).

${ }^{4}$ Expressão utilizada por Fernandes (1999, p. 238), que designa o momento quando o MST "traz a público a sua situação ao ocupar uma propriedade - um latifúndio. Conquistar a terra, uma fração do território, e se territorializar é um modo eficaz de reação e demonstração da sua forma de organização".
} 
movimentos sociais para designar formas de organização, de luta e de resistência à hegemonia burguesa ${ }^{5}$. As classes populares nos embates políticos ao poder burguês engendram formas democráticas de organização, estabelecem padrões de comportamento social e político distintos das sociedades burguesas. $O$ trabalho assume o caráter socializador e concreto, deixando de ser alienado e abstrato. Investem na formação política de seus militantes e praticam formas horizontais de decisão e de poder. Combatem os privilégios e defendem os princípios da igualdade e da solidariedade de classe. Enfim, reivindicam e praticam o internacionalismo de classe. As "invenções democráticas” devem ser compreendidas no contexto de dominação burguesa nos territórios nacionais.

A apropriação da política emancipadora pelos movimentos sociais possibilita que as relações sociais e de produção nos assentamentos do MST ou nos bairros populares dos piqueteiros ganhem novas dimensões políticas e ideológicas. A partir desses parâmetros discutimos em cada um dos movimentos as "invenções democráticas" de que são protagonistas. ${ }^{6}$

Antes de iniciarmos esta discussão, vale a pena atentar para o caráter político-ideológico bem como para a base social de cada um desses movimentos (MST e "La Verón"). Estes movimentos desenvolvem suas lutas "fora" do "núcleo duro" das relações capitalistas de produção. Confrontam-se muito mais com o Estado burguês que com o capital, propriamente dito. Explicitemos um pouco mais alguns dilemas e contradições presentes em

\footnotetext{
${ }^{5}$ Lefort está preocupado em confrontar as virtudes da democracia sobre o totalitarismo. A democracia, em seu entendimento, é portadora de direitos ou da busca pelos direitos ainda não existentes: trata-se do direito a ter direitos. Segundo Chauí, referindo-se à iniciativa dele, "a democracia é invenção porque, longe de ser a mera conservação de direitos, é a criação ininterrupta de novos direitos, a subversão contínua do estabelecido, a reinstituição permanente do social e do político. Como criação de direitos, como reconhecimento das divisões internas e das diferenças constitutivas do social e do político, a democracia abre para a história no sentido forte da palavra" (CHAUÍ, 1983, p. 11). Entretanto, cabe lembrar que a democracia burguesa pode significar o inverso também: a retirada de direitos. Basta tomarmos o exemplo da Argentina na década de 90, quando, de um lado, o Estado patrocinou políticas favoráveis à "oligarquia financeira" e, de outro, ações que visaram suprimir direitos dos trabalhadores. Estes, por sua vez, empreenderam uma luta de caráter defensivo e de sinal negativo, procurando evitar a perda de direitos conquistados há décadas. Portanto, as manifestações populares naquele país não se traduzem em lutas para a conquista de novos direitos, mas para evitar perdê-los e, nesse sentido, não empreendem uma luta de sinal positivo (COTARELO, 2000, p. 79).

${ }^{6}$ Como ressaltamos na primeira nota, os movimentos sociais que abordamos aqui foram tratados de forma exaustiva em, pelo menos, um dos capítulos da nossa tese de doutorado. Portanto, todas as ilações decorrem de pesquisa realizada junto aos acampamentos e/ou assentamentos do MST, como, por exemplo, os assentamentos da Fazenda Pirituba, no interior do Estado de São Paulo. No caso do movimento piqueteiro, também realizamos várias visitas e contatos com lideranças piqueteiras na região da Grande Buenos Aires, como explicitaremos mais adiante.
} 
suas lutas. ${ }^{7}$

Alguns autores afirmam que a implantação do modo de produção especificamente capitalista no campo ocorreu basicamente em duas fases distintas: a primeira delas entre 1958/59 a 1966 e a segunda em 1967/68. Se na primeira foi de forma localizada e tênue, portanto, restrita, na segunda conduziu a um "progressivo decréscimo populacional, provocado mormente pela aplicação da nova tecnologia e pela substituição das linhas produtivas tradicionais por modernas, melhor ajustadas às demandas da indústria e do mercado externo" (BERTERO, 2000, p. 110). Essa segunda fase se estende até os dias de hoje e "são indiscutíveis os efeitos de todo esse processo sobre as relações sociais. Muitas das quais cedem lugar às relações puramente assalariadas. Cresce, conseqüentemente, a proletarização. $O$ proletariado rural ganha maior projeção. Enfim, o tão aguardado protagonista social das esquerdas entra em cena". 8

Germer (2002) também considera a agricultura brasileira capitalista e em rápido processo de desenvolvimento. Assim, para ele, a sua estrutura de classes está cada vez mais polarizada entre burguesia e proletariado. Em linhas gerais, o campo brasileiro tem a seguinte composição social: grande burguesia agrária (10,6\%), média burguesia (8,2\%); camada intermediária: pequena burguesia $(16,7 \%)$, produtor simples $(9,8 \%)$; força de trabalho $(54 \%)$, entre semiassalariados e proletariado (permanentes e temporários). ${ }^{9}$

Para os objetivos de nossa análise, os dados sobre a composição de classe são importantes por dois motivos básicos: em primeiro lugar, porque revelam que o desenvolvimento do capitalismo no campo está ligado à uma burguesia agroindustrial: "As lavouras dos produtores capitalistas são, em sua maioria, formadas por culturas de exportação, mais rentáveis e de rentabilidade mais

\footnotetext{
${ }^{7}$ Embora as discussões tomam como base a atuação política do MST, elas servem, em certo sentido, para entendermos também os movimentos piqueteiros, já que se compõem, predominantemente, de trabalhadores desempregados, portanto, "fora" do confronto direto com o capital. As bases sociais de ambos os movimentos não se confrontam diretamente com o capital: nem aqui nem lá podem, por exemplo, paralisar a produção de mercadorias.

${ }^{8}$ Bertero (2000, p. 110). afirma que, no final dos anos 60, esse processo fomentou, no mundo acadêmico, inúmeros artigos, dissertações, teses: "Tinha-se a impressão de que a proletarização era inevitável e inexorável; que tudo desaguaria nela ou conduziria a ela; que a modernização seria avassaladora e homogeneizadora; que redundaria, fatalmente, na homogeneização proletária". Mas, adverte ele: "Perdeu-se de vista a diversidade, para a qual só se voltará a atenção a contar de meados da década de 70 , ocasião em que se dá uma verdadeira reviravolta nos estudos agrários, com a ascensão do pequeno produtor e a conseqüente perda de primazia atribuída ao proletário. Esse novo personagem, que ficará conhecido entre nós como camponês, erige-se, consoante muitos, no novo sujeito da história"

${ }^{9}$ Dados obtidos do IBGE: Censo Agropecuário de 1995/96 (apud BUZETTO, 2002, p.19). Alguns esclarecimentos: considera-se como grande burguesia agrária os proprietários rurais com área superior a 100 ha; a média burguesia, entre 50-100 ha; a pequena burguesia, entre 20-50 ha; e os semiassalariados com menos de 20 ha.
} 
estável, utilizando tecnologias desenvolvidas (como a soja/trigo, milho empresarial, cana-de-açúcar, laranja, cacau etc.) ou culturas de mercado interno de amplo consumo, como o arroz [...]" (GERMER, 2002, p. 270).

Em segundo lugar, porque ajuda a compreender melhor que o MST: tem a sua base social predominantemente no semiproletariado agrário, isto é, entre os pequenos agricultores semi-autônomos (aqui denominados semi-assalariados), cuja área total é menos que 20 hectares e que ou não têm terra própria, ou não têm sequer equipamentos de tração animal para o seu trabalho, ou não possuem ambos. Este é o segmento em que as contradições com o desenvolvimento capitalista da agricultura são mais acentuadas, o que origina uma postura mais contundente de contestação ao sistema estabelecido [...]. Apesar da heterogeneidade de situações concretas existentes no interior do segmento de pequenos agricultores semiproletarizados, eles apresentam, entretanto, uma homogeneidade maior no plano político, pelo fato de que a estrutura capitalista da agricultura os exclui e esmaga inapelavelmente (GERMER, 2002, p. 276).

O proletariado propriamente dito, ou seja, os "assalariados puros" estão fora da base do MST. Segundo Germer, esse setor não constitui, politicamente, a camada dirigente da classe trabalhadora rural, a despeito de sua significativa expressão numérica. Por sua vez, embora tendo influência sobre os sindicatos de trabalhadores rurais assalariados, a CUT (Central Única dos Trabalhadores) hesita em apostar no processo de organização dessa luta, preferindo manter-se ligada aos pequenos produtores de mercadorias. Considerando-se a posição e o papel político desempenhado pelo semiproletariado, deparamo-nos com um paradoxo:

Em primeiro lugar, a sua situação concreta de classe está mais próxima do proletariado rural, entretanto, este mantém-se vinculado à organização - o DNTR ${ }^{10}$ da CUT -, que congrega principalmente pequenos produtores de mercadorias, com os quais as suas afinidades concretas são muito menores, enquanto o semiproletariado possui a sua própria organização - o MST. [...] Em segundo lugar, embora o proletariado rural constitua o segmento que tem, concretamente, as contradições mais agudas com a estrutura capitalista, é o semiproletariado que assume, através do MST, a posição de luta mais contundente contra o sistema, através da sua bandeira principal, que é a reforma agrária sob o controle dos trabalhadores (GERMER, 2002, p. 281).

Essas questões sinalizam algumas dificuldades políticas enfrentadas pelo MST para organizar as suas bases, pois, do ponto de vista político-ideológico e das necessidades concretas, os "assalariados puros" e os "semiproletários"

${ }^{10}$ Departamento Nacional de Trabalhadores Rurais, hoje inexistente na estrutura organizacional da CUT. Em seu lugar foi criada a Confederação Nacional dos Trabalhadores Agrícolas (Contag). 
são dois setores do campo popular muito próximos. Porém, no plano concreto da luta não trilham os mesmos caminhos, a não ser em algumas ocasiões especiais como ocorreu durante a Marcha dos 100 mil sobre Brasília, em 1999. Levando-se em conta que o "proletariado puro" é numericamente superior ao "semiproletariado", as coisas se complicam ainda mais, dado o potencial de luta que o primeiro poderia engendrar em conjunto com o "semiproletariado" e não o faz: a Contag, representante desse segmento, tem 15 milhões de filiados e a CUT totaliza 21 milhões (Comparato, 2003). Por outro lado, o MST, que representa o "semiproletariado", tem apenas 250 mil famílias ou 500 acampamentos e 1.500 assentamentos. ${ }^{11}$

Segundo Bertero (2000, p114), a sociabilidade capitalista chegou ao campo e é crescente em seu meio,

a produção de mercadorias por meio de mercadorias, em regra industrializadas, em escala igualmente crescente. É por intermédio da absorção destas mercadorias industrializadas que ela, agropecuária, altera a sua base técnica e, com esta, o seu modo de produzir, que se assimila ao da indústria. A essa assimilação denomina-se industrialização. Tal industrialização atinge amplamente a população rural.

O MST tem clareza de suas limitações e se depara com elas à medida que se esforça para superá-las procurando ampliar seu leque de atuação no campo popular. Germer (2002), entretanto, chama a atenção para o paradoxo que existe com o fato de o "proletariado puro" ou o trabalhador assalariado hoje não se constituir no setor dirigente das lutas no campo, mas sim o "semiproletariado" organizado em torno do MST. Bertero, de outro lado, crítica o protagonismo dos sem-terra, considerando-o extemporâneo, pois as lutas do proletariado urbano e rural são, nas condições atuais do desenvolvimento capitalista, praticamente as mesmas: "Tudo indica que, ao se aprofundarem as transformações no campo e elevar o nível de organização e consciência dos trabalhadores, especialmente os assalariados, o acesso à terra não mais poderá permanecer figurando como bandeira unitária do sindicalismo". Por esse ângulo, "a terra é, segundo se viu, convertida em capital. Razão pela qual a sua reivindicação é extemporânea” (BERTERO, 2000, p. 119).

\footnotetext{
11 Comparato faz uma segunda comparação: o número de greves (Contag) com o número de ocupações (MST e Contag). Nos anos de 1997 e 1998, as greves foram superiores ao número de ocupações: 462 ocupações contra 563 greves em 1997; 446 ocupações contra 580 greves em 1998. A partir daí, Comparato tira duas conclusões: "em primeiro lugar, a visibilidade de uma organização não depende de seu tamanho. Em segundo lugar, ocupações de terras têm chamado muito mais a atenção do que greves. Esse resultado já era esperado, pois as ocupações de terra e a defesa da reforma agrária vão de encontro ao sistema de propriedade privada [...]" (COMPARATO, 2003, p. 136-137).
} 
Estas críticas, ao se voltarem apenas para a análise do núcleo duro das relações de produção, perdem a dimensão política das lutas do MST, ou seja, o questionamento ao regime jurídico de propriedade. Os sem-terra, portanto, atacam a propriedade privada, especialmente nos planos políticojurídico e ideológico, mas o impacto de suas lutas não atinge diretamente o núcleo duro das relações econômicas de produção. Em outros termos, os avanços, potencialidades e limites de suas lutas estão umbilicalmente ligados à crise do movimento operário contemporâneo.

\section{MST: "ocupar, resistir e produzir"12}

A luta pela reforma agrária do MST (Movimento dos Trabalhadores Rurais Sem Terra) ultrapassa a distribuição de terra e tem se politizado bastante. Mesmo o proletariado puro não compondo a base social do MST, o movimento dá sinais da possibilidade de construção de uma sociedade socialista. Seus assentamentos têm se mostrado não somente "ilhas de resistência" ao neoliberalismo como também espaços reais de construção de novas relações sociais e de produção, mesmo sob a hegemonia burguesa. Trata-se, indiscutivelmente, de redutos populares de contra-hegemonia. Assim, a bandeira da reforma agrária ganha atualidade política e ideológica: em primeiro lugar, ao imprimir-lhe uma identidade de classe popular contra a burguesia agrária; em segundo, ao apontar as contradições e limites do capitalismo; em terceiro, ao sinalizar formas de produção anticapitalistas, mesmo sob o domínio burguês; e, finalmente, ao universalizar a luta como potencialmente pertencente a todos os trabalhadores explorados e expropriados pelo capital.

O MST tem se destacado no cenário das lutas populares brasileiras pelas ocupações de terras e marchas. Além de ocupar terras consideradas improdutivas e que não cumprem a função social prevista na Constituição de 1988, os sem-terra ocupam prédios públicos - como a sede do Instituto Nacional de Colonização e Reforma Agrária, órgão do Ministério do Desenvolvimento Agrário -, agências bancárias etc. Em 1997 e 1999, o movimento realizou duas importantes marchas pelo país que lhe renderam repercussões internacionais. Em 1997, entre 17 de fevereiro e 17 de abril, os caminhantes realizaram a Marcha Nacional por Emprego, Justiça e Reforma Agrária, quando percorreram mais de 1.000 quilômetros a pé. Em 1999, entre

\footnotetext{
${ }^{12}$ Não reconstituiremos a trajetória política do MST desde o seu surgimento em 1984. Há inúmeros trabalhos que se referem à história do movimento e, dentre eles, destacamos os seguintes: Harnecker (2002); Gohn (2000); Petras (1997); Fernandes (1999); Stedile e Fernandes (1999); Bogo (2003); Zibechi (1999); Mauro e Pericás (2001); Morissawa (2001); Buzetto (2002); Pagotto (2003); Mauro (1999); além de publicações de autoria do próprio MST: jornal, revista, cartilhas, panfletos, Internet etc.
} 
26 de julho e 7 de outubro, a Marcha Popular pelo Brasil, cujo lema "terra, trabalho e democracia”, mobilizou mais de 100 mil pessoas. Foi um evento de importância política especial para os movimentos sociais em geral, por ter sido coordenado por um amplo leque de forças políticas, dentre eles o MST, CUT, CMP (Central dos Movimentos Populares), MMTR (Movimento de Mulheres Trabalhadoras Rurais), MPA e CNBB (Confederação Nacional dos Bispos do Brasil). ${ }^{13}$

Nos acampamentos do MST, normalmente submersos no calor da luta política mais imediata - polícia, justiça, jagunços etc. - os sem-terra praticamente vivem em estado permanente de assembléia. As discussões e avaliações políticas coletivas são muito importantes e visam garantir a permanência de todos no acampamento. Os sem-terra chegam a viver quatro anos embaixo da lona-preta e, sem dúvida alguma, é um exercício "pedagógico" fundamental para a formação política de cada um. Nesse período, crianças,adolescentes, homens, mulheres, idosos "fazem" política diuturnamente. ${ }^{14}$

Quando comparado aos acampamentos, os assentamentos apresentam um quadro político distinto. E, por isso, entendemos que os desafios do MST aumentam. Por se situarem em outro patamar da luta de classes, os assentamentos não vivem em estado de assembléia permanente e nem se encontram no calor da luta política mais imediata. Neles, os sem-terra vão plantar e colher aquilo que faz parte de suas reservas políticas e ideológicas, ou seja, o que entendem que seriam as relações de produção socialistas. Ao lado desse aspecto, um outro desafio se interpõe: a capacidade política de se

\footnotetext{
${ }^{13}$ Os anos de 1999 e 2000 foram de grandes mobilizações que envolveram outros movimentos sociais, como a Contag e o Movimento dos Pequenos Agricultores (MPA): "O ano de 1999 terminou com mais de 500 acampamentos do MST, agrupando em torno de 72 mil famílias. E, de acordo com um estudo feito pelo próprio governo, só há espaço na atual política agrícola para 600 mil proprietários rurais. Os 4,2 milhões restantes ficarão marginalizados. [...]. Na semana de 17 a 24 de abril de 2000, que incluía as comemorações dos 500 anos do descobrimento do Brasil, o MST ocupou mais de 150 latifúndios improdutivos no país, envolvendo perto de 20 mil famílias" (MORISSAWA, 2001, p. 163).

${ }^{14}$ Fora essas, as relações sociais nos acampamentos tendem a mudar: homens cozinham e cuidam das crianças enquanto as mulheres fazem a segurança; todos se inserem em algum setor (segurança, educação, saúde, higiene, alimentação, almoxarifado etc.) e, portanto, assumem alguma tarefa no acampamento; todos fazem curso de formação política; e as crianças e adultos são alfabetizadas, normalmente pelo "método Paulo Freire". Uma das principais lições dos acampamentos é a prática da solidariedade de classe e a distribuição coletiva do que recebem como doação. As principais refeições também são compartilhadas por todos. Não generalizamos estas observações, pois se referem à nossa visita a um acampamento do interior de São Paulo. É provável que em outras partes do país, devido às especificidades culturais, sociais, econômicas, políticas e ideológicas, algumas questões assumem mais importância que outras. Para efeito de esclarecimento, entre os anos de 2001 e 2003, vistamos o acampamento "Chico Mendes" (Jacareí - SP), o pré-assentamento Fazenda Santa Rita (São José dos Campos - SP) e dois assentamentos: Paranacity (PR) e Itapeva/ Itaberá (SP), na Fazenda Pirituba. No assentamento da Fazenda Pirituba tivemos a oportunidade de realizar várias visitas em praticamente todas as suas seis áreas.
} 
manter vinculado ao movimento. ${ }^{15}$ Os assentamentos do movimento representam o seu maior desafio, visto que concretizam a possibilidade de "construção antecipada do socialismo”. Sob a hegemonia burguesa neoliberal, o desafio se torna ainda maior, porque o Estado, representando os interesses comuns das classes dominantes, procura inviabilizá-los. Como a luta não é apenas econômica, mas principalmente política e ideológica, o Estado conta com o apoio dos grandes meios de comunicação para isso. ${ }^{16}$

Os assentamentos do MST não são todos organizados da mesma maneira. ${ }^{17}$ Estes são, em linhas gerais, os aspectos político-ideológicos do MST nos assentamentos da Fazenda Pirituba. Como sabemos, dada a dimensão territorial brasileira e a complexidade que assume a luta pela terra em cada região do país, não generalizamos essas observações.

As "invenções democráticas" no MST ou em qualquer outro movimento social não estão imunes às contradições próprias das sociedades capitalistas. Em um mesmo espaço político ou em uma mesma fração territorial convivem práticas democráticas e de inspiração socialista com formas políticas vinculadas à ideologia burguesa. No MST, o "novo" e o "velho" são disputados no mesmo espaço geográfico.

\section{"La Verón": "trabajo, dignidad y cambio social" 18}

Os chamados "cortes de ruta" ou "cortes de calle" se transformaram nas principais formas de protesto nos anos 90 ao lado das greves gerais. Segundo Carrera e Cotarelo (1999), nesse período a Argentina viveu nove greves gerais, declaradas por uma ou várias centrais sindicais. A maior parte delas se concentrou em 1995 e 1996 e se distribuiu pelos principais cordões industriais do país: Grande Buenos Aires, Rosario, Córdoba, e em certas cidades e regiões do interior, como Mar del Plata, Chaco, Noroeste, Entre Ríos, Río Negro. Para termos uma idéia do grau de mobilização, nas greves com menor

\footnotetext{
${ }^{16}$ Segundo Comparato (2003, p. 119), "os documentos extraídos da imprensa [...] sugerem que haja uma concordância, em todos os veículos jornalísticos, no sentido de apresentar negativamente o MST".

${ }^{17}$ Com uma base social predominantemente constituída por "semi-assalariados", os desafios do MST aumentam se imaginarmos uma cultura patriarcal, individualista e machista que muitos camponeses trazem consigo. Os riscos de não quererem trabalhar a terra de forma coletiva são constantes ou de preferirem o lote individual. Para isso, a vida coletiva nos acampamentos aliada à formação política do movimento são fundamentais para provocarem mudanças nas consciências conservadoras desses homens e mulheres. Nos acampamentos as práticas coletivas não envolvem a questão da propriedade privada, que se dará de fato no assentamento. Mas a forma de luta coletiva para conquistar a terra tem um efeito pedagógico que pode provocar a adesão dos mais conservadores ao trabalho coletivo posterior, ou pelo menos que mantenha alguma forma de cooperação nos assentamentos.

${ }^{18}$ Referirmo-nos à pesquisa que realizamos junto ao movimento piqueteiro argentino "La Verón", entre os anos de 2001 e 2003.
} 
adesão dos trabalhadores, o percentual não foi menor que 50\%. As greves de 1995 e 1996 foram as de maior adesão: 70 e 90\% dos trabalhadores, além das grandes cidades do interior. Coincidência ou não, elas foram realizadas quando os índices de desemprego e subemprego alcançaram seus níveis mais altos, chegando a quase $30 \%$ da população economicamente ativa. ${ }^{19}$



Gráfico 1- Evolução Anual dos Conflitos Trabalhistas (1980-2003)

Fonte: Centro de Estudios Nueva Mayoría (2004)

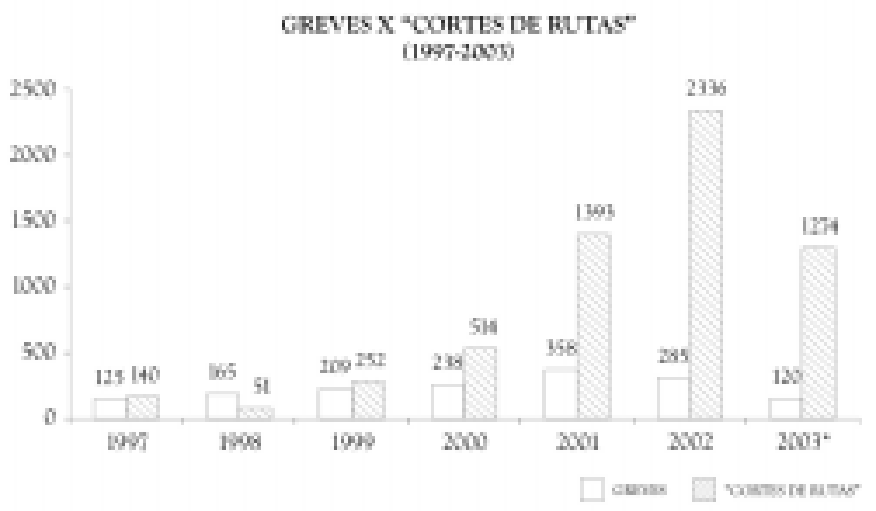

Gráfico 2 - Greves x "Cortes de rutas"

Fonte: Centro de Estudios Nueva Mayoría (2004)

\footnotetext{
${ }^{19}$ De acordo com Carrera e Cotarelo (1999, p.147, "en el desarrollo de las huelgas generales se pueden señalar tres momentos: uno entre 1992 y 1994, en que existe fractura entre los cuadros sindicales, una adhesión mayor al 50\% de los trabajadores a las huelgas generales y relativo aislamiento social del movimiento obrero; otro en 1995 y 1996, en que los cuadros sindicales alcanzan su mayor grado de unidad en la acción, se produce la mayor cantidad de huelgas generales, que alcanzan la mayor adhesión entre los trabajadores y reciben el más extendido apoyo desde otras fracciones de sociedad; un tercero desde 1997 hasta 1999, en que hay nuevamente fractura entre los cuadros sindicales, menos huelgas generales, menor adhesión de los trabajadores y mayor aislamiento social".
} 
A despeito das mobilizações sindicais alcançarem índices surpreendentes até meados da década de 1990, observamos o seu declínio nos anos seguintes ao lado da ascensão dos movimentos piqueteiros:

Consideramos os "cortes de ruta" ou "bloqueio de estradas" como uma das principais "invenções democráticas"

dos movimentos piqueteiros: com um instrumento poderoso nas mãos, os piqueteiros passaram a criar novas subjetividades e novas relações de poder; as massas populares exercitam a contra-hegemonia nas ruas e nos bairros, e não mais exclusivamente nas fábricas; com isso, rechaçam a dominação burguesa, suas instituições repressivas, exigem do Estado políticas sociais voltadas aos seus interesses de classe.

Os piqueteiros só podem ser pensados a partir de sua organização em movimentos sociais. Fora dos movimentos eles são desempregados. Por isso, admitimos que quando se organizam, criticam não apenas a relação capitaltrabalho, mas também as condições que os subjugam quando estão "fora" dela. ${ }^{20}$ O piqueteiro é uma "construção" social, política e ideológica de resistência das classes populares na quadra histórica de confronto com a hegemonia neoliberal. A formação da classe operária não é determinada apenas na sua relação direta com os meios de produção, pois há outros fatores envolvidos: político, cultural, objetivo, subjetivo. $O$ que também não quer dizer que as relações de produção não sejam "a referência última das classes sociais. Os lugares ocupados no processo de produção, basicamente a grande divisão fundamental entre proprietários não-trabalhadores e trabalhadores não proprietários, é a divisão fundamental que possibilita a organização de coletivos com interesses opostos" (BOITO JR., 2003, p. 244).

Essa referência fundamental é apenas latente. Ao contrário da formação da burguesia que, sob o capitalismo, já está formada como classe social,

para que a classe operária, que existe apenas em potência no terreno da economia capitalista, adquira uma existência ativa, é necessária a combinação de inúmeros fatores de ordem econômica, política e ideológica - situação do emprego e do salário, situação do sistema de alianças que sustenta o bloco burguês no poder, eficácia da ideologia e do programa socialistas para responder aos problemas colocados na ordem do dia pela sociedade capitalista numa determinada etapa de seu desenvolvimento etc. A classe social só existirá no sentido forte do termo, isto é,

\footnotetext{
${ }^{20}$ Eles questionam, portanto, "las relaciones sociales alienantes en la producción (es decir [questionam] la difusión social de la producción y la lógica mercantil en todos los planos) que se manifiestan de modo concreto en el plano intersubjetivo, mucho más que las relaciones de producción" [grifos do autor] (MAZZEO, 2004, p. 8).
} 
como coletivo organizado e ativo, quando o antagonismo latente tornar-se manifesto (BOITO JR., 2003, p. 245).

Os piqueteiros politizaram a sua condição de desempregados. Portanto, se essa condição pressupõe que o trabalhador não é nada quando está "fora" das relações de produção, a de piqueteiro "conlleva un reconocimiento de que el desocupado excede las relaciones de producción, es 'algo' por fuera de ellas. La identidad piquetero en sus dimensiones laborales, políticas y simbólicas, se ha sido conformada por fuera de la interioridad de la relación capital-trabajo pero también por fuera de la frustración de quedar al margen de ella" (MAZZEO, 2004, p. 8). ${ }^{21}$

Entre os diversos movimentos piqueteiros, ${ }^{22}$ identificamos o "La Verón" (Movimiento de Trabajadores Desocupados "Aníbal Verón”) como aquele que se diferencia dos demais e que, por isso mesmo, priorizamos em nossas análises. ${ }^{23}$

"La Verón” procura antecipar a "construção do socialismo" em suas bases de resistência, nos locais onde vivem, em seus bairros. Para eles, a "democracia de base" é mais ampla que a "horizontalidade": "Reafirmando la idea de igualdad, define una concepción de organización que 'armoniza' las decisiones de base con el funcionamiento de una estructura organizativa que

\footnotetext{
${ }^{21}$ Alguns autores preferem diferenciá-los a partir das novas subjetividades atribuídas a eles: "El desocupado es un sujeto determinado por la necesidad, definido por una carencia. El piquetero es alguien condicionado pero no determinado por la misma necesidad. La diferencia es mayor: el piquetero ha logrado producir una operación subjetiva sobre un fondo socialmente precario. No puede negar su condición, pero tampoco se somete a ella. Y en ese acto subjetivador se apropia de sus posibilidades de acción, de subjetivación" [grifos dos autores] (COLECTIVO SITUACIONES, 2002, p. 100).

${ }^{22}$ Há inúmeros movimentos piqueteiros na Argentina e esse processo continua aberto, ou seja, podem surgir ainda outros. Dentre os que mais se destacam, entretanto, seja pela capacidade de mobilização ou pela visibilidade política com que aparecem, salientamos alguns: Desocupados Unidos en Lucha (DUL); Unión de Trabajadores Desocupados (UTD); Corriente Clasista y Combativa (CCC); Movimiento de Desocupados Teresa Rodríguez (MTR); Movimiento de Trabajadores Argentinos (MTA); Movimiento Democrático Popular (MDP); Federación Tierra y Vivienda (FTV); Movimiento Independiente de Jubilados y Desocupados (MIJD); Frente Única de Trabajadores Desocupados (Futrade); Movimiento Territorial de Liberación (MTL); Polo Obrero (PO); Coordinadora de Trabajadores Desocupados "Aníbal Verón" (CTD "Aníbal Verón”); Movimiento de Trabajadores Desocupados "Aníbal Verón" ("La Verón”); Movimiento de Trabajadores de La Matanza (MTD La Matanza); Movimiento "Barrios de Pie"; Frente de Trabajadores Combativos (FTC); Movimiento Sin Trabajo Teresa Vive (MST); Coordinadora de Unidad Barrial (CUBa); Movimiento de Trabajadores Desocupados Resistir y Vencer (MTD Resistir y Vencer); Frente Barrial 19 de diciembre; Movimiento Sin Trabajo de La Matanza (MST La Matanza).

${ }^{23} \mathrm{O}$ movimento piqueteiro "La Verón" se apresenta da seguinte forma ao procurar se diferenciar dos demais movimentos piqueteiros: "Para que esa sociedad que deseamos sea posible, tenemos que empezar a practicarla desde ahora. Todos los días organizando nuestro trabajo, nuestras actitudes, nuestras relaciones, con dignidad, justicia y igualdad. A mal puerto van a dar las experiencias que depositan sus ideales en futuros tan puros como remotos, que se contradicen con prácticas cotidianas donde prima la soberbia, las jerarquías y el desprecio al prójimo (MOVIMIENTO DE TRABAJADORES DESOCUPADOS “ANÍBAL VERÓN”, 2003a, p. 2).
} 
naturalmente toma forma en la medida en que crecen nuestros movimientos" (MOVIMIENTO DE TRABAJADORES DESOCUPADOS "ANÍBAL VERÓN, 2003a, p. 3). Dada às características que assumiu, ou seja, agrega em torno de si mais de 15 MTD's, é fácil reconhecer que se trata, portanto, de um "movimento de movimentos". Em suas manifestações, principalmente nos "cortes de rutas", chega a mobilizar quase dez mil pessoas. A horizontalidade, para os militantes de "La Verón”, pressupõe igualdade no acesso à informação, ao conhecimento e à formação política de todos. ${ }^{24}$

O desemprego em massa provocado pela reestruturação capitalista nos anos 90, juntamente com todo o processo de privatização das empresas estatais, obrigou os trabalhadores a voltarem para os bairros. ${ }^{25}$ Os piquetes, portanto, transferiram o eixo do conflito da fábrica para os bairros (MOVIMIENTO DE TRABAJADORES DESOCUPADOS "ANÍBAL VERÓN", 2003b, p. 149). ${ }^{26}$

\section{Algumas conclusões preliminares}

Os piqueteiros e os sem-terra parecem sinalizar que o centro da luta de classes é mais amplo que aquilo que, convencionalmente, uma parte dos marxistas aponta como a contradição fundamental entre a burguesia e os assalariados puros. Os piqueteiros e os sem-terra se confrontam diretamente com a dominação do capital, mesmo se encontrando "fora" das relações de produção capitalista. Na prática, questionam o aparente paradoxo entre o "assalariado puro" que, em tese, deveria ser o protagonista da revolução e eles, o "exército industrial de reserva", em tese "contra-revolucionários", que se colocam à frente dos processos de transformação social. Ora, ao adquirirem identidade coletiva e lutarem pela transformação do capitalismo, assumem, como classe, o papel que, teoricamente, caberia aos trabalhadores diretamente ligados às relações sociais de produção capitalista.

\footnotetext{
${ }^{24}$ Tivemos a oportunidade de acompanhar um dos cursos de formação política promovido pelos movimentos de Almirante Brown, Lanús e Quilmes, em maio de 2003. A maioria dos participantes, entre 20 e 30, era de pessoas simples, com pouca ou média escolaridade. Havia crianças, adolescentes, mulheres e homens de diversas faixas etárias, embora predominasse um público mais jovem (entre 17 e 25 anos).

${ }^{25}$ É interessante notar a forte presença de mulheres piqueteiras. Em conversa com várias delas e indagadas sobre o fato de serem maioria, explicaram que os homens, em geral, têm dificuldades para participarem do movimento, pelo menos num primeiro momento. Eles se sentiam culpados pela situação de desemprego e, em função disso, as mulheres foram assumindo a luta. Com o passar de alguns anos, os movimentos foram conquistando algumas vitórias e muitos deles acabaram se integrando ao movimento. Além disso, as mulheres tiveram mais facilidades para a luta piqueteira porque, ao contrário da maioria dos homens que saia para trabalhar nas fábricas, "viviam" mais o bairro, cuidavam dos filhos, conheciam os vizinhos, as escolas, o comércio local etc.

${ }^{26}$ É importante ressaltar que o capital não se abstém da disputa territorial. Ao contrário, todo o processo que possibilita a construção ideológica de identidade coletiva é disputado pelo capital.
} 
Como os trabalhadores desempregados - caso dos piqueteiros - ou os "semi-assalariados" - caso dos sem-terra - não estão em condições subjetivas de tomar a dianteira do processo revolucionário - entre outros motivos porque perderam força política e ideológica durante a implantação do projeto neoliberal -, os novos protagonistas, ao assumirem a tarefa da revolução, propõem novas formas para realizá-la. Ou seja, não estão sendo nos mesmos moldes até então conhecidos.

Esses "novos" sujeitos, potencialmente revolucionários, desafiam os ícones da democracia burguesa (liberdade, igualdade, fraternidade) e apresentam à sociedade suas "invenções democráticas": democracia direta, decisões por assembléia, trabalho concreto e compartilhado, horizontalidade, igualdade de gênero, acesso à informação e à formação política a todos. Trata-se daquilo que arriscamos chamar de "construção antecipada do socialismo" em práticas aparentemente cotidianas, mas que sinalizam para mudanças mais profundas nas relações capitalistas.

\section{REFERÊNCIAS}

BERTERO, J. F. Sobre a questão agrária. Revista Mediações, Londrina, v. 5, n. 1, p. 109 122, jan.-jun. 2000.

BOGO, A. Arquitetos de sonhos. São Paulo: Expressão Popular, 2003.

BOITO Jr., A. A (difícil) formação da classe operária. In: BOITO Jr., A.; TOLEDO, C. N. de. (Org.). Marxismo e ciências humanas. São Paulo: Xamã, 2003.

BUZETTO, M. O antiimperialismo na luta do MST: questão agrária e questão nacional na construção de um projeto popular para o Brasil. 2002. 152 f. Dissertação (Mestrado em Ciências Sociais) - Programa de Estudos Pós-Graduados em Ciências Sociais, Pontifícia Universidade Católica, São Paulo.

CARRERA, N. I.; COTARELO, M. C. Clase obrera y protesta social en la Argentina de los '90. Revista América Libre, Buenos Aires, n. 16, p. 143-152, dic. 1999.

CENTRO DE ESTUDIOS NUEVA MAYORÍA. Evolución anual de los conflictos laborales. 2004. Disponível em: <www.nuevamayoria.com>. Acesso em: 15 fev. 2005.

CENTRO DE ESTUDIOS NUEVA MAYORÍA. Huelgas y cortes de ruta. 2004. Disponível em: 〈www.nuevamayoria.com>. Acesso em: 15 fev. 2003.

CHAUÍ, M. Apresentando o livro de Lefort. In: LEFORT, C. A invenção democrática: os limites da dominação totalitária. São Paulo: Brasiliense, 1983.

COLECTIVO SITUACIONES. 19 y 20: apuntes para el nuevo protagonismo social. Buenos Aires: De mano en mano, 2002.

COMPARATO, B. A ação política do MST. São Paulo: Expressão Popular, 2003.

COTARELO, M. C. La protesta en la Argentina de los '90. Revista Herramienta: revista de debate y crítica marxista, Buenos Aires, n. 12, p. 139-148, oto. 2000.

FERNANDES, B. M. MST: Movimento dos trabalhadores rurais sem terra: formação e territorialização em São Paulo. São Paulo: Hucitec, 1999. (Geografia: teoria e realidade, 37). 
GERMER, C. O desenvolvimento do capitalismo no campo brasileiro e a reforma agrária. In: STÉDILE, J. P. (Org.). A questão agrária hoje. Porto Alegre: Ed. UFRGS, 2002.

GOHN, M. da. G. Mídia, terceiro setor e MST: impactos sobre o futuro das cidades e do campo. Petrópolis: Vozes, 2000.

HARNECKER, M. Sin Tierra: construyendo movimiento social. Madrid: Siglo XXI de España Editores, 2002.

LEFORT, C. A invenção democrática: os limites da dominação totalitária. São Paulo: Brasiliense, 1983.

MACHADO, E. R. Mal-estar da democracia no Brasil e na Argentina nos anos 90: lutas sociais na contramão do neoliberalismo. São Paulo, 2004. 239 f. Tese (Doutorado em Ciências Sociais) - Programa de Estudos Pós-Graduados em Ciências Sociais, Pontifícia Universidade Católica de São Paulo.

MAURO, G. MST: lutas e perspectivas. In: BARSOTTI, P.; PERICÁS, L. B. (Org.). América Latina: história, crise e movimento. São Paulo: Xamã, 1999.

MAURO, G.; PERICÁS, L. B. Capitalismo e luta política no Brasil: na virada do milênio. São Paulo: Xamã, 2001.

MAZZEO, M. Piqueteros: notas para una tipologia. Buenos Aires: FISyP, 2004.

MORISSAWA, M. A história da luta pela terra e o MST. São Paulo: Expressão Popular, 2001.

MOVIMIENTO DE TRABAJADORES DESOCUPADOS “ANÍBAL VERÓN”. Nuestra política para construir un presente y un futuro con trabajo, dignidad y cambio social. (mimeo.), jun. 2003a.

MOVIMIENTO DE TRABAJADORES DESOCUPADOS “ANÍBAL VERÓN”. Dario y Maxi, dignidad piquetera: el gobierno de Duhalde y la planificación criminal de la masacre del 26 de junio en Avellaneda. Buenos Aires, 2003b.

PAGOTTO, C. Ajustes e rupturas: cooperativismo e lutas sociais no Brasil contemporâneo. 2003. 144 f. Dissertação (Mestrado em Ciências Sociais) - Programa de Estudos PósGraduados em Ciências Sociais, Pontifícia Universidade Católica. São Paulo,

PETRAS, J. Neoliberalismo en América Latina: la izquierda devuelve el golpe. Rosario: Homo Sapiens Ediciones, 1997.

RUDÉ, G. Ideologia e protesto popular. Rio de Janeiro: Zahar, 1982.

STEDILE, J. P.; FERNANDES, B. M. Brava gente: a trajetória do MST e a luta pela terra no Brasil. São Paulo: Fundação Perseu Abramo, 1999.

ZIBECHI, R. La mirada horizontal: movimientos sociales y emancipación. Montevideo: Nordam Comunidad, 1999. 
